\title{
Tu Quoque Arguments and the Significance of Hypocrisy
}

\author{
SCOTT F. AIKIN
}

Dept. of Philosophy and Religion

Western Kentucky University

1906 College Heights Blvd., Cherry Hall, Room 300

Bowling Green, Ky. 42101

U.S.A.

scott.f.aikin@vanderbilt.edu orscott.aikin@wku.edu

\begin{abstract}
Though textbook $t u$ quoque arguments are fallacies of relevance, many versions of arguments from hypocrisy are indirectly relevant to the issue. Some arguments from hypocrisy are challenges to the authority of a speaker on the basis of either her sincerity or competency regarding the issue. Other arguments from hypocrisy purport to be evidence of the impracticability of the opponent's proposals. Further, some versions of hypocrisy charges from impracticability are open to a counter that I will term tu quoque judo.
\end{abstract}

Resumé: Quoique les exemples d'arguments tu quoque dans les manuels sont des sophismes qui transgressent la pertinence, plusieurs arguments basés sur l'hypocrisie se rapportent à ce sujet. Certains arguments établis sur 1'hypocrisie questionnent soit la sincérité ou soit la compétence d'un interlocuteur sur un point en litige afin de contester son autorité. D'autres arguments qui emploient l'hypocrisie donnent l'impression d'appuyer le jugement que les propositions d'un adversaire sont impraticables. En outre, certaines versions d'une accusation d'hypocrisie bâtie sur l'impraticabilité peuvent être contrariées par ce que je nommerai le judo tu quoque.

Keywords: Tu Quoque, Hypocrisy, Fallacy, Informal Logic, Argumentation

1.

Tu quoque arguments are ad hominem arguments wherein a speaker (B) charges another (A) with inconsistency on an issue of dispute. ${ }^{1}$ The

\footnotetext{
${ }^{1}$ Here, I will be restricting the use of ad hominem argumentation to what Hamblin (1970) termed the standard contemporary take on the fallacy of inferring qualities of views from the qualities of those who hold them. This is distinct from the tradition of ad hominem argumentation stretching from Aristotle to Locke to Johnstone wherein all arguments are tailored to fit the commitments of the audience. This classification of $t u$ quoque as a sub-specie of ad hominem is standard, though challenged (in Walton 1992, 212). Given the analysis that follows, I will argue that in some forms, tu quoque arguments are both ad homienem and ad rem. For textbook endorsements of the standard classification of $t u$ quoque as a specie of ad hominem, see: Engel $(1982,158)$, Hurley (1994, 121), Perkins (1995, 158), Govier (1997, 180), van Eemeren and
}

(C) Scott Aikin. Informal Logic, Vol. 28, No. 2 (2008), pp. 155-169. 


\section{Scott Aikin}

charge of inconsistency may, on the one hand, be cognitive, in that a contradiction is derivable from A's overt (or suppressed) commitments. A claims that $\mathrm{p}$, but A may have also claimed that not-p elsewhere, or A may have other commitments which together entail not-p. On the other hand, A's inconsistency may be practical-A's actions contradict A's explicitly endorsed proposals, which amounts to hypocrisy. ${ }^{2}$

I will focus here only on practical versions of tu quoque arguments, arguments from hypocrisy. Although textbook tu quoque arguments are generally classified as fallacies of relevance, I will argue many versions of arguments from hypocrisy may be interpreted as bearing indirectly on the issue of dispute. Some arguments from hypocrisy are challenges to the authority of a speaker on the basis of either her sincerity or competency regarding the issue. Other arguments from hypocrisy purport to be evidence of the impracticability of the opponent's proposals. A further consideration regarding these impracticability arguments from hypocrisy is that some are open to a counter that I will term tu quoque judo.

\section{2.}

Tu quoque arguments are deployed to undermine the views of a dialectical opponent on the basis of inconsistency on her part regarding a matter at issue. Take the textbook form of argument from hypocrisy:

TQ1 1. A advocates that plan $a$ be followed on the basis of proposition $\mathrm{p}$.

2. A does not follow $a$.

3. Therefore, $\mathrm{p}$ is false or $a$ is not worthy of being followed on the basis of A's advocacy.

Textbook tu quoque arguments share ad hominem's general mantle of fallacies of relevance - the hypocrisy of the arguer is not necessarily evidence of the falsity of what she argues. However, one may feel a gut feeling there is something right about tu quoque arguments in that the acceptability of the view proposed is challenged. ${ }^{3}$ Take the following:

Grootendorst (2004, 177), Fogelin and Sinnott Armstrong (2005, 381), Moore and Parker (2007, 177), and Vaughn (2008, 178).

2 The division here between cognitive and hypocritical inconsistency recapitulates Woods and Walton's (1976) fourfold distinction of tu quoque arguments into logical and assertional (here both termed cognitive) and praxiological and praxiological-deontic (here both termed practical-hypocritical).

${ }^{3}$ Trudy Govier captures the thought here by noting even the most principled philosopher has the "gut reaction" to such a display "amounting sometimes to rage" (1981, 3). 


\section{Smoker Dad}

A: You shouldn't smoke, son. It's bad for your health, and it's addictive.

B: Look at you, dad! You smoke, too! You don't have the right to lecture me.

This seems a textbook version of tu quoque argument; however, B has not explicitly concluded anything regarding A's proposals. However, given that B's contribution to the discussion is properly interpreted as a challenge to A's proposal, we should have a default interpretive stance that B is offering an argument relevant to either A's proposed action $a$ or proposition $\mathrm{p}$. The problem is that, again, textbook interpretations of arguments from hypocrisy take them to claim immediate relevance to the conclusions that $\mathrm{p}$ is false or $a$ is not worth following - that A's inconsistency bears directly on p's truth value and $a$ 's acceptability. It does not follow, given A's smoking, that A's proposal that B should not smoke is false, nor that it is false that smoking is unhealthy and addictive. However, we certainly would say B expresses natural indignation with A. Note further that B does not say that what A says is false or not worth doing, but rather that A's hypocrisy undermines his credibility. So an alternate interpretation of such an argument may run:

TQ2 1. A proposes that plan $a$ be followed on the basis of $\mathrm{p}$.

2. A does not follow $a$.

3. Therefore, A is insincere in proposing $a$ or $\mathrm{p}$ (or both).

4. Sincerity is a necessary condition for authority.

5. Therefore, $\mathrm{A}$ is not a legitimate authority regarding $a$ or $\mathrm{p}^{4}$

The charge of hypocrisy is that of direct inconsistency of word and deed. With each of these cases, B's response to A's proposal is that A's actions are a better guide as to A's commitments than what A actually says, so TQ2 arguments run off of a principle connecting TQ2-1 and 2 with 3 -namely, that:

Actions Speak Louder than Words (ASLW): If any speaker (S) claims that $a$ ought to be followed on the basis of $\mathrm{p}$ but $\mathrm{S}$ fails to act in accord with $a$ or $\mathrm{p}$, then either $\mathrm{S}$ is not in fact committed to $a$ or $\mathrm{p}$ or S's real commitment is to not-p or not- $a$ (or both).

If the consequent of this principle is true, then in its employment with TQ2, we have evidence that A is not sincere in proposing that $a$ or $\mathrm{p}$, and so $\mathrm{A}$ is not a legitimate authority on $a$ or $\mathrm{p} .{ }^{5}$ Far from being irrelevant to

\footnotetext{
${ }^{4}$ This schema is derived from Govier's "more plausible" version of tu quoque (1981).

${ }^{5}$ This is a regular requirement of deference to authority - that what we believe on the basis of the authority is what the authority actually believes.
} 


\section{Scott Aikin}

the acceptability of A's proposed actions and propositions, A's consistency and sincerity are important considerations in $\mathrm{B}$ reasonably assessing A's claims as authoritative. That is, if $\mathrm{A}$ is an authority with regard to $\mathrm{p}$ or $a$, A should be giving what she takes to be the truth of the matter with regards to these things - if she does not give her considered opinion on the matter, then what is the use of her authority?

Relatedly, charges of double standards have similar dialectical bite, as they do not directly bear on the acceptability of the opponent's claim, but on the opponent's trustworthiness with the issue. However, the double standard charge sticks only in the condition that the inconsistent cases are sufficiently similar. For example, take the following:

\section{Daddy's Bedtime}

A: You need to go to bed at 7:30 — everyone needs a good night's sleep.

B: But daddy, you stay up much later than I do!

Bedtimes are double standards only if those going to bed need the same amount of sleep. The problem with B's charge here is that adults do not need as much sleep, so A's bedtimes do not have to match up with B's. B does not know this, so from B's perspective, this is a legitimate complaint, and the objection allows A to clarify the issue. So all $t u$ quoque arguments require that for hypocrisy/double standards charges to bear on the claims and proposals at issue, the circumstances of A's actions and those of the proposals be similar. So TQ2's premises 1 and 2 must be revised:

TQ2-1': A proposes that in circumstances $X, a$ be followed on the basis of $p$.

TQ2-2': A does not follow $a$ in circumstances $\mathrm{X}$ or in similar circumstances.

The circumstances here are ones defined by the relevance conditions for the appropriateness of doing a in light of $\mathrm{p}$ - so with Smoker Dad, the facts of health consequences and their undesirability conjoined with their association with smoking makes it so that unless there are worse evils to be avoided or if one has good reason to believe the consequences will not follow, one has reason not to smoke. The fact that those conditions obtain for both A and B makes A's proposal and actions a case of hypocrisy on a double standard. With Daddy's Bedtime, bedtimes for small children are set by the amount of sleep children need for proper brain development, but those amounts are not needed for adult brains. And there is coffee. As a consequence, B's early and A's late bedtimes does not constitute a case of double standard.

ASLW is a second weak point in the TQ2 argument from hypocrisy as many can be committed to claims (and hence, be sincere) but not be personally capable of following through: 


\section{Vegetarian Barbecue}

A: Eating meat is morally wrong.

B: Yeah, but when I took you to the world's greatest barbecue, you said that just once, and then you devoured a plate of ribs.

Hypocrisy charges stick best (or are at least most damaging to a speaker's sincerity) when A's actions arise from stable habits or practices. If it is a one-off case of A yielding to smoky Kansas City temptation, A's failure to follow her own advice hardly makes her a hypocrite nor does it weaken the view that $\mathrm{A}$ is sincere in holding her view. A's being weak-willed makes her still an object of disapproval, but she is not a hypocrite in the relevant sense of undermining her sincerity requisite for authority. She is still sincere in her commitment, and her failure of will is irrelevant to the truth or falsity of her view or whether or not she knows it true. A may even say something like, "I did eat that plate of ribs. I was weak, and I do try to keep to my principles. The fact that they are delicious doesn't make it OK, it just makes it hard. I do mostly eat vegetarian." 6

The point is that if A has a stable habit of not following her own proposals (perhaps regularly stopping at the pit barbecue for lunch), then A is truly insincere. What constitutes regularity will be relative to the perceived vice (gambling, drinking, etc.). One-off cases do not constitute hypocrisy for A. There must be a tolerance zone between those who follow their own advice and those who are insincere or incompetent hypocrites. As a consequence, TQ2-2 must be revised as follows:

TQ2-2"': A regularly (or as a matter of habit) does not follow $a$ in circumstances X.

That is, unless there is a real and regular failure of character, as opposed to momentary failure of willpower, we are not necessarily in the presence of hypocrisy that undermines conditions for sincerity. This is partly because the nature of hypocrisy, as it is not simply inconsistency of word and deed, but requires also dissemblance (which drives the charge of insincerity). That is, with hypocrisy charges, the hypocrite must not only make claims and proposals, but she must present herself as a model for those claims. Her inconsistency, then, is not just about her sincerity with regard to the claims, but with regard to what a model she is and whether she genuinely holds her proposals.

A further general constraint on tu quoque arguments is that if there is an inconsistency, the inconsistency must be either contemporaneous or close enough in time to yield real hypocrisy. Take, for example:

\footnotetext{
${ }^{6}$ Thanks to Tony Lloyd for discussion regarding this point.
} 
160 Scott Aikin
Altarboy Atheist:
A: There's no answer to the problem of evil. God doesn't exist—and
if he does, he's certainly not worthy of our worship.
B: You can't possibly really believe that-you were an altarboy!

The problem is that B says A was an altarboy. And the longer ago it was, the less conflict there is between A's actions and words. If A's altarboy tenure was up 30 years ago, it does not seem inconsistent for $\mathrm{A}$ to have changed his mind since then. Moreover, if worship services for A were part of a childhood in a religious house, then later atheism is less inconsistency but more making one' own decisions. People change their minds. So there have to be two features of A's actions: (i) they must be A's own mature actions, and (ii) they must be within a sufficiently close time frame. Importantly, we mark (ii) in natural language by punctuating hypocrisy charges against A proposing that $\mathrm{p}$ with A "at the same time" or "then turning right around" and doing not-p. So TQ2-2 needs to be further revised:

TQ2-2"': A regularly (or as a matter of habit) does not follow $a$ in circumstances $\mathrm{X}$ within a short period before or after proposing $\mathrm{p}$.

The (qualified) schema with TQ2 is promising. However, it does not capture what happens in all forms of tu quoque hypocrisy charges, as it seems there are cases where either the contradiction between word and act is either a more general tension or is a direct tension between the words and deeds of a third authority on the matter. Let us look first at the hypocrisy of authorities.

A familiar pitfall for may social and political discussions is that many who are visible and vocal leaders in these discussion are not always perfect in how they live up to what they propose be done. In the same way that in Smoker Dad, A's smoking stands as a challenge to his sincerity and hence his authority, any public authority's hypocrisy with regard to her area of proposal is taken as grounds for suspicion and challenge. Take the following exchanges as exemplary:

\section{Gore's Airplane}

A: Have you seen An Inconvenient Truth? Al Gore makes the case that global warming is serious. We need to do something.

B: Ah, but Gore travels around in airplanes. What a hypocrite!

\section{Chomsky's Investments}

A: Noam Chomsky makes a good case that we should hold our economic investments to a moral standard.

B: Uh, yeah, but you know his own portfolio is filled with investments in things he claims to find abhorrent-oil companies, military contractors, and drug companies. 
Here, the hypocrisy charge B makes is not against A, but against A's preferred authority. This application of the hypocrisy charge, then, is a modification of TQ2, but instead of B using TQ2 against the speaker she is directly challenging (A), B uses it against A's authority (C). As such, these strictly are not TU quoque arguments, but are more $I S$ (he) or EA (she) quoque arguments, in that they are arguments from the hypocrisy of some third party. I am not interested here in piling terminology up deeper than necessary here, so I will stick with tu quoque as the name of the general argumentative move, but these are different styles of arguments. ${ }^{7}$ Here is a schematic version of the third-personal deployment of TQ2:

TQ3 1. A proposes that $a$ be followed in circumstances $\mathrm{X}$ on the basis of $p$.

2. A argues that $a$ should be followed and $\mathrm{p}$ is true on the basis of C's proposals of $a$ and $\mathrm{p}$.

3. C regularly does not follow $a$ in circumstances $\mathrm{X}$.

4. Therefore, $\mathrm{C}$ is insincere with $a$ and $\mathrm{p}$.

5. Sincerity is a necessary condition for authority.

6. Therefore, $\mathrm{C}$ is not a legitimate authority regarding $a$ and $\mathrm{p}$.

7. Therefore, A's proposals that $a$ and $\mathrm{p}$ are not well supported.

It is clear that TQ3 is related to TQ2, since in TQ2, B goes after A's hypocrisy, and in TQ3, B goes after C's hypocrisy to undermine the sincerity required for legitimate authority. In both Gore's Airplane and Chomsky's Investments cases, those who argue from or make use of the claims for either authority must answer for the sincerity of these authorities. Importantly, TQ3 has a powerful rhetorical edge, since those who are the public face for intellectual and social movements will not only be scrutinized for the case they make for their proposals, they will be scrutinized for their own behavior. The appeal of some program or movement is often dependent on the appeal of its leaders, and so TQ3 is designed to undercut such appeal. But the fact that TQ3 is rhetorically strategic does not yet make it fallacious or irrelevant. ${ }^{8}$ If an authority is insincere in proposing something, that undermines the warrant we would have in accepting her advice. The publicity of authority, at once, intensifies scrutiny, but it also consequently increases expectations of consistency. As with TQ2, hypocrites are those who make themselves out to be models for their proposals, and their inconsistency, as a consequence, is all the more poignant. With TQ3, authorities are held to a

\footnotetext{
${ }^{7}$ Thanks to one of the anonymous reviewers for pointing out the structural differences between Smoker Dad and Gore's Airplane. Though, again, I hold that the central move of the arguments are the same, this difference is significant and must be reflected by different schemata for the arguments.

${ }^{8}$ For accounts of how rhetorically strategic moves may nevertheless be consistent with the objectives of non-fallacious critical dialogue, see van Eemeren and Houtlosser (1999) and Krabbe (2004).
} 


\section{Scott Aikin}

demanding standard of conduct in the areas in which they are authoritative.

People can be hypocrites and damage their authority not just by failing to do what they propose, but by failing in a broader range of related concerns. With TQ1, TQ2, and TQ3, we have cases of direct contradiction of word and deed. However, it is clear there may be a more general tension. For example:

\section{Drinker Dad}

A: You shouldn't smoke, son. It's bad for your health, and it's addictive.

B: Look at you, dad! You drink too much and you're a womanizer! You don't have the right to lecture me.

Here there is no direct contradiction between what A says and what A does. How A's drinking and womanizing are relevant to the issue is that A's suggestion as to how to live well is undermined by A's not taking similar kinds of advice. So A lacks authority about smoking. The following schema captures the thought:

TQ4 1. A proposes that $a$ be followed in circumstances $\mathrm{X}$ on the basis of $\mathrm{p}$.

2. $a$ and $\mathrm{p}$ are in area $\alpha$.

3. Propositions $(\mathrm{q}, \mathrm{r}, \mathrm{s}, \ldots)$ and proposals $(b, c, d, \ldots)$ and are in area $\alpha$.

4. $(\mathrm{q}, \mathrm{r}, \mathrm{s}, \ldots)$ are true and $(b, c, d, \ldots)$ are to be followed on their basis.

5. If $[(\mathrm{q}, \mathrm{r}, \mathrm{s}, \ldots)$ and $(b, c, d, \ldots)$ are in area $\alpha,(\mathrm{q}, \mathrm{r}, \mathrm{s}, \ldots)$ are true and $(b, c, d, \ldots)$ are to be followed, and A either fails to be committed to the truth of $(\mathrm{q}, \mathrm{r}, \mathrm{s}, \ldots)$ or follow $(b, c, d, \ldots)]$, then $\mathrm{A}$ is not an authority in $\boldsymbol{\alpha}$.

6. A regularly fails to follow $(b, c, d, \ldots)$ within a short time of proposing $a$ and $\mathrm{p}$.

7. Therefore, A does not hold that $(\mathrm{q}, \mathrm{r}, \mathrm{s}, \ldots)$ is true.

8. Therefore, $\mathrm{A}$ is not an authority in $\boldsymbol{\alpha}$.

9. If $a$ and $\mathrm{p}$ are in area $\alpha$, then $\mathrm{A}$ is a legitimate authority regarding $a$ and $\mathrm{p}$ only if $\mathrm{A}$ is an authority in $\boldsymbol{\alpha}$.

10. Therefore, $\mathrm{A}$ is not a legitimate authority regarding whether $a$ or $\mathrm{p}$.

TQ4 addresses A's authority to suggest $a$ or speak to p, given A's track record in and general views on matters in $\boldsymbol{\alpha}$. A standard requirement for authority is a good track record and competent outlook, and repeated or egregious errors in $\alpha$ undermine expertise in that area. A similar argument has been made in the wake of revelations of William Bennett's (who once wore the mantle of virtue-czar) gambling habits: 


\section{Bennett's Gambling:}

A: William Bennett seems right on about the virtues of integrity and honesty - and we ought to expect that of our leaders.

B: Bill Bennett the gambling addict? Please! How does he have the moral authority to criticize anybody?

B's argument is designed to diminish Bennett's moral authority on the basis of Bennett's own (purportedly) similar failings. The question, however, is whether the virtues and the moral question of high stakes poker are sufficiently similar to be put in the same area of concern. The crucial thing is that the overlap in $\boldsymbol{\alpha}$ be clear. It seems relevant enough with Drinker Dad, but with Bennett's Gambling, it seems a stretch, as gambling may be a vice in excess, but the vices Bennett criticized (dishonesty, disloyalty, cowardice) are vices wherever they are seen. That Bennett gambles (and the question is open as to whether his was excessive to begin with) then does not make him a hypocrite with regards to what he says about honesty, loyalty, and bravery.

It should be noted, however, that there is an important structural difference between Drinker Dad and Bennett's Gambling. It is analogous to the difference between Smoker Dad and Gore's Airplane. In Drinker Dad, B goes after A's hypocrisy and thereby undermines A's case for $\mathrm{p}$ and $a$. In Bennett's Gambling, B goes after the hypocrisy of A's authority (C), and thereby undermines A's case for $\mathrm{p}$ and $a$. As a consequence, Bennett's Gambling needs to be rendered according to the following schema:

TQ5 1. A proposes that $a$ be followed in circumstances $\mathrm{X}$ on the basis of $\mathrm{p}$. 2. A argues that $a$ and $\mathrm{p}$ on the basis of C's authority.

3. $a$ and $\mathrm{p}$ are in area $\boldsymbol{\alpha}$.

4. Propositions $(\mathrm{q}, \mathrm{r}, \mathrm{s}, \ldots)$ and proposals $(b, c, d, \ldots)$ and are in area $\alpha$.

5. $(\mathrm{q}, \mathrm{r}, \mathrm{s}, \ldots)$ are true and $(b, c, d, \ldots)$ are to be followed on their basis.

6. If $[(\mathrm{q}, \mathrm{r}, \mathrm{s}, \ldots)$ and $(b, c, d, \ldots)$ are in area $\boldsymbol{\alpha},(\mathrm{q}, \mathrm{r}, \mathrm{s}, \ldots)$ are true and $(b, c, d, \ldots)$ are to be followed, and A either fails to be committed to the truth of $(\mathrm{q}, \mathrm{r}, \mathrm{s}, \ldots)$ or follow $(b, c, d, \ldots)]$, then $\mathrm{C}$ is not an authority in $\boldsymbol{\alpha}$.

7. C regularly fails to follow $(b, c, d, \ldots)$ within a short time of proposing $a$ and $\mathrm{p}$.

8. Therefore, $\mathrm{C}$ does not hold that $(\mathrm{q}, \mathrm{r}, \mathrm{s}, \ldots)$ is true.

9. Therefore, $\mathrm{C}$ is not an authority in $\boldsymbol{\alpha}$.

10. If $a$ and $\mathrm{p}$ are in area $\alpha$, then $\mathrm{C}$ is a legitimate authority regarding $a$ and $\mathrm{p}$ only if $\mathrm{C}$ is an authority in $\alpha$. 
11. Therefore, $\mathrm{C}$ is not a legitimate authority regarding whether $a$ or $\mathrm{p}$.

12. Therefore, A's case for $a$ and p on the basis of C's authority is not well-supported.

Again, like with Gore's Airplane, B's argument runs that since A's chosen authority is illegitimate, A's proposal is not warranted. The difference, however, is that with TQ3, the case is made on the purported authority's insincerity. In the case of TQ5, the case is made on the basis of the authority's incompetence in her area of purported expertise.

The question still remains as to what TQ4's premise 5 and TQ5's premise 6 amount to so that if any speaker (S) fails to meet a certain threshold of commitments or actions, $\mathrm{S}$ has no authority (and in these cases, moral authority). For that matter, there is a question as to what moral authority is. There is not space for an analysis of moral authority here, but it seems clear that we should prefer advice from some as opposed to others in terms of how we esteem their track record and competence not only on the issue at hand, but on broadly related matters. I do not seek marriage advice from someone I know who beats his wife. Neither from someone who's a racist.

One final clarification is necessary. Tu quoque arguments often suffer from irrelevance not only to the claim at issue, but to the cases for the claims. So far, we have only surveyed the former. The broad concern is that if $t u$ quoque argument is out to undermine A's authority, it misses A's argument for $a$. That is, if A gives an argument for $a$ from $\mathrm{p}$, then questions of A's hypocrisy seem irrelevant to $a$ and to A's case for it. ${ }^{9}$ If $\mathrm{A}$ is a hypocrite but argues for $a$ (and presumably also for $\mathrm{p}$ ) and $\mathrm{B}$ cannot object to the arguments, then B's tu quoque is superfluous. The same goes for A's authorities - they, presumably, give arguments, too. B's move, again, is strategic-B is perhaps losing the discussion regarding $\mathrm{p}$ and the actions $(a)$ that are appropriate, so $\mathrm{B}$ shifts the discussion to A's character, where B can score some points. If B is successful in keeping the discussion about A or A's authority $\mathrm{C}$ instead of $\mathrm{p}$ or $a$, then $\mathrm{B}$ may even claim victory by making the discussion uncomfortable for $\mathrm{A}$ and forcing $\mathrm{A}$ to bow out or shaming $\mathrm{C}$ into public silence. By this, tu quoque arguments create a culture of deliberative hostility, where speakers make each other pay a social price for having views. This is certainly a vicious consequence of tu quoque argumentation.

However, tu quoque arguments that place a speaker's (S) sincerity and competence in question $d o$ place their arguments in question. If $\mathrm{S}$ is insincere or incompetent in $\boldsymbol{\alpha}$, then it is reasonable that though S's argument may seem valid it is likely composed of cherrypicked evidence or it fails to address standard challenges in the field. Surely it makes sense to ask $\mathrm{S}$ why, if the argument for $\mathrm{p}$ and how it

\footnotetext{
${ }^{9}$ Thanks to one of the anonymous reviewers for pressing this point.
} 
bears on $a$ is so good, S fails to follow $a$. An interlocutor (B), given this incongruence, has good reason to take it that the issue regarding $a$ is not as simple as S's argument portrays it. As such, S's inconsistency with the issue is what one may call meta evidence about S's arguments - namely, that they are likely not reflective of the quality required for assent in the area of concern. ${ }^{10}$ Surely it is right that B would not be well-served by ignoring A's suggestions in Smoker Dad, and this is certainly troubling. The point here is that the evidence of the intellectual character of one's interlocutor or her chosen authorities can undo one's trust in the arguments she gives: if you think the person opposite you is insincere or incompetent, you may reasonably be suspicious. Bad arguments easily masquerade as good arguments for those not familiar with areas of study, ${ }^{11}$ and if we have reason to believe that a speaker is dissembling in this way, skepticism is the right attitude.

\section{3.}

Not all $t u$ quoque arguments are irrelevant to the opponent's claim. Conservative political critic Peter Schweizer has famously noted: "If their liberal prescriptions don't really work for them as individuals, how can they really work for the rest of us?" $(2005,15)$. If a person believes that the plan is most preferable, that person should be highly motivated to follow that plan. So with people who have the means and motives to follow their own advice, how they live their lives is evidence of the practicability and hence acceptability of that advice:

TQ6 1. A proposes that $a$ be followed in circumstances $X$ on the basis of $p$

2. If A proposes that $a$ be followed, then A holds that A should follow $a$ in $\mathrm{X}$ or similar circumstances.

3. If A holds A should follow $a$, then barring defeaters A will regularly follow $a$.

4. Defeaters for A following $\mathrm{p}$ are that A lacks the minimal resources to follow $a$, the circumstances are not similar, or following $a$ is not practicable.

5. If $a$ is not practicable, then $a$ should not be followed.

6. A does have the means to follow $a$ and the circumstances are similar to X.

7. A regularly does not follow $a$

8. Therefore, $a$ is not practicable

9. Therefore, $a$ should not be followed.

\footnotetext{
${ }^{10}$ See Johnstone's (1952) argument that ad hominem demonstration of what I have termed cognitive inconsistency shows the thinker in question is confused. This is a practical version of this argumentative strategy.

${ }^{11}$ See Talisse and Aikin (2006) for an account of how this happens with straw man arguments.
} 
So if A doesn't practice what he preaches, then B has evidence that what A preaches isn't worth following. What TQ4 may concede is that A's proposal $a$ is nice, but A's actions reveal it as idealistic. That A lives in the real world and doesn't follow $a$ shows that $a$ is excessively demanding. From a philosophical perspective, TQ4 arguments are instantiations of the regulative principle that ought implies can:

Ought-Can: A ought to perform $a$ only if A can perform $a$.

The thought behind Ought-Can is that A can be held responsible only for what is in A's control. So if A cannot perform $a$, A cannot be held responsible for performing $a$, and as a consequence, A should not be required to perform $a$. This seems on its face a perfectly reasonable principle for advice, and there is a good deal of philosophical agreement of its appeal. ${ }^{12}$ In its application of ought-can, TQ4 is an interpretation of the modality of 'can' as 'practicably can'. There is some question as to what this means.

Take Gore's Airplane also as an IS (he) quoque version of TQ6. Since we have seen that the second and third personal pairings (TQ2 and 3, and TQ4 and 5) all share the same underlying structure, I will treat TQ6 arguments as having the same central elements. The point is that Gore himself surely could take the available means of reducing his 'carbon footprint' by no longer traveling on an airplane, but for him, this is not a viable option. Nor is it really a viable option for many of us. The problem, though, is the dearth of options other than business as usual-if enough people wanted those options and if we applied our intelligence toward developing them, then the institutional impediments to taking those steps will be alleviated. But if it is done individually, we have people making excessive sacrifices.

Analogize the situation for Gore with the situation of a passenger in the midst of a train robbery. If all the passengers rush the robber, then they could incapacitate him and be out of danger. But if only one or a small few do so, they will be shot and considerably worse off. Someone complaining about the situation holding that we should all rush the robber is himself not a hypocrite if he does not rush the robber just by himself. The Gore situation is roughly similar in that if we all (and this includes governmental and industrial cooperation) effected a change, then we would not only address the problems on the table, but also maintain a reasonably good standard of living (there may have to be some sacrifices, though). However, if we do not have this widespread

\footnotetext{
${ }^{12}$ Ought-Can is a widely accepted principle for a number of norms including ethical, political, and cognitive. That the principle is appropriate for the cognitive realm has been challenged in Aikin (2005), Saka (2000), Wolterstorff (1997) and SinnottArmstrong (1984).
} 
cooperation, then what do we do? Does not taking the proposed option, given lack of cooperation, amount to hypocrisy?

Schweitzer reports that Chomsky, when faced with Chomsky's Investments, responded, "What else can I do? .... Should I live in a cabin in Montana?"(2005, 31). Schweitzer calls this a "rhetorical dodge," thinking it is a case of an idealist who refuses to see the realist in his mirror. However, the question is what conclusion follows - is it that those who invest can't avoid investing in morally objectionable enterprises? Is it that no one in a first world country can avoid being complicit with a variety of industrial or economic injustices? But isn't this something worth criticizing, regardless of whether one's personal actions are inconsistent with the criticism? Moreover, is it not a criticism of a failure of broad cooperation? Is the only other option, if one hews to the critical project, to completely check out of contemporary culture?

Gore's airplane works on similar lines, and to its detriment. If Al Gore, a man aware of the hypocrisy charge, is motivated and has maximal means available to him to avoid them, nevertheless cannot avoid the charges of hypocrisy, then his criticism of contemporary culture and industry must be all the more correct. Gore may be a hypocrite in the sense that he cannot follow his own advice, but his hypocrisy is, in fact, evidence of how little has been done to address the problem of carbon emissions on the side of government regulations and industrial innovation. What Gore's hypocrisy shows for Gore is how far we have to go.

The image of this strategy is that of taking the argumentative momentum of a certain TQ6 argument against those who employ it. As a consequence, I call it 'tu quoque judo.' The thought is that if A is making a recommendation $a$ as part of a larger program of criticism, of which $p$ is a relevant part, and A cannot follow $a$ because of the things pointed out by the larger critical program, then A may be a hypocrite in a sense, but A's hypocrisy demonstrates the poignancy of A's critical project. So there is a sense in which Al Gore should thank the hypocrisy corps rallied by the Right - they are helping him make his point.

Analogize the dialectical situation with Smoker Dad. A says that given the connection between smoking and health problems and addiction, B shouldn't smoke. B points out to A that A nevertheless smokes. A, then, is revealed as someone who holds that people shouldn't smoke but who also smokes. A is revealed as someone who cannot help but do something he holds as wrong or bad. This is the hallmark of addiction-A, presumably, even holds that A shouldn't smoke, but A nevertheless smokes. Contrary to B's thought that A's smoking undermines A's case that B shouldn't smoke, it strengthens it. ${ }^{13}$

\footnotetext{
${ }^{13}$ Thanks go to the editors and reviewers at Informal Logic, and to James Bednar, Caleb Clanton, Allen Coates, Carolyn Cusick, Lenn Goodman, Tony Lloyd, Mason Marshall, Brian Ribeiro, Aaron Simmons, Robert Talisse, Jeffrey Tlumak, Linda Zagzebski, and audiences at the Tennessee Philosophical Association and Hendrix College for their many helpful comments on earlier drafts of this paper.
} 


\section{References}

Aikin, Scott F. (2005) “Who's Afraid of Epistemology's Regress Problem?” Philosophical Studies. 126. 191-217.

Eemeren, Frans H. van and Grootendorst, Rob. (2004) A Systematic Theory of Argumentation: The pragma-dialectical approach. New York: Cambridge University Press.

Eemeren, Frans H. van and Houtlosser, Peter. (1999) "Strategic Manoevering in Argumentative Discourse." Discourse Studies. 1. 479-497.

Engel, Morris. (1982) With Good Reason: An Introduction to Informal Fallacies. $2^{\text {nd }}$ Edition. New York: St. Martin's.

Fogelin, Robert J. and Sinnott-Armstrong, Walter. (2005) Understanding Arguments: An Introduction to Informal Logic. Belmont, CA: Wadsworth.

Govier, Trudy. (1981) "Worries About Tu Quoque as a Fallacy." Informal Logic Newsletter. 3, 2-4.

Govier, Trudy. (1997) A Practical Study of Argument $4^{\text {th }}$ ed. Belmont, CA: Wadsworth.

Hamblin, C. L. (1970) Fallacies. London: Methuen

Hurley, Patrick. (1994) A Concise Introduction to Logic. $5^{\text {th }}$ Edition. Belmont, CA: Wadsworth.

Johnstone, Henry W. Jr. (1952) "Philosophy and Argumentum ad Hominem." The Journal of Philosophy, 49:15. 489-498.

Krabbe, Eric C.W. (2004) "Strategies in Rhetoric and Dialectic." In Argumentation and its Applications: CD-ROM. Proceedings from the Conference of the Ontario Society for the Study of Argumentation. Ed. Hans V. Hansen, Christopher Tindale, J. Anthony Blair, Ralph H. Johnson and Robert C. Pinto (Eds.).

Moore, Brooke Noel and Parker, Richard.. (2007) Critical Thinking. $8^{\text {th }}$ Edition. New York: McGraw Hill.

Perkins, Ray, Jr. (1995) Logic and Mr. Limbaugh. Chicago: Open Court.

Saka, Paul. (2000) "Ought Does Not Imply Can." American Philosophical Quarterly. 37:2. 93-105.

Schweizer, Peter. (2005) Do As I Say (Not As I Do): Profiles in Liberal Hypocrisy. New York: Random House

Sinnott-Armstrong, Walter. (1984) "Ought Conversationally Implies Can." The Philosophical

Review. 93:2. 249-261.

Talisse, Robert and Aikin, Scott F. "Two Forms of the Straw Man." Argumentation (2006) 20:345-352

Vaughn, Lewis. (2008) The Power of Critical Thinking: Effective Reasoning About Ordinary and Extraordinary Claims. $2^{\text {nd }}$ Edition. New York: Oxford University Press. 
Tu Quoque and Hypocrisy 169

Walton, Douglas. (1992) The Place of Emotion in Argument. University Park, PA: Penn State University Press.

Wolterstorff, Nicholas. (1997) "Obligations of Belief - Two Concepts." In The Philosophy of Roderick Chisholm. Ed. Lewis Edwin Hahn. La Salle, IL: Open Court. 217-38.

Woods, John and Walton, Douglas. (1976) "Ad Hominem." Philosophical Forum. 8:1. 1-20 